\title{
Fault Modeling and Simulation of Memristor based Gas Sensors
}

\author{
Saurabh Khandelwal*, Anu Bala*, Vishal Gupta ${ }^{\dagger}$, Marco Ottavi ${ }^{\dagger}$, Eugenio Martinelli ${ }^{\dagger}$ and Abusaleh Jabir* \\ *School of ECM, Oxford Brookes University, UK. Email: (skhandelwal, 15057719, ajabir)@brookes.ac.uk \\ †Electronic Engg., University of Rome “Tor Vergata”, Italy. Email: vishal.gupta@students.uniroma2.eu, \\ (ottavi, martinelli)@ing.uniroma2.it
}

\begin{abstract}
Memristors are an attractive option for use in future architectures due to their non-volatility, high density and low power operation. Gas sensing is one of the proposed application of memristive devices. In spite of these advantages, memristors are susceptible to defect densities due to the nondeterministic nature of nano-scale fabrication. In this paper, a novel spice memristor model incorporating fault models that emulates the gas sensing behaviour with/without faults is developed for simulation and integration with design automation tools. Our simulation results show that the proposed non-linear model detects the presence of the oxidising/reducing gas and analyses the defects/faults affecting the functionality of the sensor.
\end{abstract}

Index Terms-Memristor, Gas Sensor, Spice, Defects

\section{INTRODUCTION}

$\mathrm{TiO}_{2}$ metal oxide semiconductor was used by HP Labs to fabricate the first physical memristive device [1]. Generally, when semiconducting metal oxide are used as gas sensor, the main cause of change of the sensor's resistance is due to the loss (gain) of the free charge carriers (electrons or holes) from (to) the semiconductor to (from) its surface [2]. The intial and final resistances of the device after gas exposure are measured and the gas properties of such gas are determined from the measured values. Gas sensing can be prone to measurement and reliability issues due to defect/faults in the device itself. The goal of this paper is to introduce a fault model for memristive sensors and to simulate them with an ad-hoc developed SPICE model. The likely defects are those based on existing literature, nonetheless the model is flexible so that it could be modified to include fault observed from manufactured devices.

\section{Proposed Memristor Gas Sensor Model}

In this paper, a non-linear gas sensor model is first proposed based on generally accepted assumption, $R_{\mathrm{on}}$ is directly exposed to the target gas and becomes $R_{\text {OnEff }}$ upon exposure [3]. The relationship between $R_{\text {on }}$ and $R_{\text {OnEff }}$ is as follows.

$$
\begin{aligned}
& \frac{R_{\mathrm{OnEff}}}{R_{\mathrm{On}}}=1+A C^{\beta} \text { [Reducing gas] } \\
& \frac{R_{\mathrm{OnEff}}}{R_{\mathrm{On}}}=\frac{1}{1+A C^{\beta}} \text { [Oxidising gas] }
\end{aligned}
$$

where, $A$ and $\beta$ are fitting parameters, $C$ is the concentration of the gas. The model uses (3) and (4) to compute initial memristance $R_{\mathrm{M}}^{\mathrm{I}}$ and final memristance $R_{\mathrm{M}}^{\mathrm{F}}$ of the device after exposure to $C$ ppm of gas [3]-[5].

$$
\begin{aligned}
& R_{\mathrm{M}}^{\mathrm{I}}=R_{\mathrm{on}} \cdot e^{\lambda_{\mathrm{I}} \cdot\left(x-x_{\mathrm{on}}\right) /\left(x_{\mathrm{off}}-x_{\mathrm{on}}\right)} \\
& R_{\mathrm{M}}^{\mathrm{F}}=R_{\mathrm{OnEff}} \cdot e^{\lambda_{\mathrm{F}} \cdot\left(x-x_{\mathrm{on}}\right) /\left(x_{\mathrm{off}}-x_{\mathrm{on}}\right)}
\end{aligned}
$$

where, $\lambda_{\mathrm{I}}=\ln \left(\frac{R_{\text {off }}}{R_{\text {on }}}\right), \lambda_{\mathrm{F}}=\ln \left(\frac{R_{\text {off }}}{R_{\text {OnEff }}}\right), x_{\text {on }} \leq x \leq x_{\text {off }}$. The Spice model shown in Fig. 1 will facilitate easy integration and simulation of memristor-based sensors with design automation tools. The model was built on the basic memristor model presented in [4] and further expanded in [5]. The model can be explained as follows: Line 3 allows the faults to be injected. The effective resistance after exposure to gas is calculated by line 4 . Line 5 represents the state variable derivative. The window function [4] to ensure state variable $x$ remains within the 0 and D boundary is restricted by line 6 . Line $8-12$ offers non-linear $\mathrm{V}$ to I conversion. Circuit to determine state variable is computed from line 13-15. Finally line 16-17 exhibit current source representing memristor.

\section{A. Defects Classification}

Defects in memristors based gas sensor are the physical structures that deviate from the intended layout design and caused by imperfection in the fabrication process [6].

1) Open Defect (OD): 'Open' within the cell, underdoped/insufficient dopant [6] cause the memristor resistance to be extremely high, independent of any gas applied across the device.

2) Short Defect (SD): This defect decreases the resistivity of the memristor owing to a fully doped cell or a 'short' within the cell, independent of any gas applied across it.

3) Surface Contamination Defect (SCD): This defect arises due to impurities that settle on $\mathrm{TiO}_{2-\mathrm{X}}$ oxide surface and can affect the physical and sometimes chemical properties of the oxide [7]. A gas sensor with SCD provides inaccurate/reduced value after exposure to gas. 


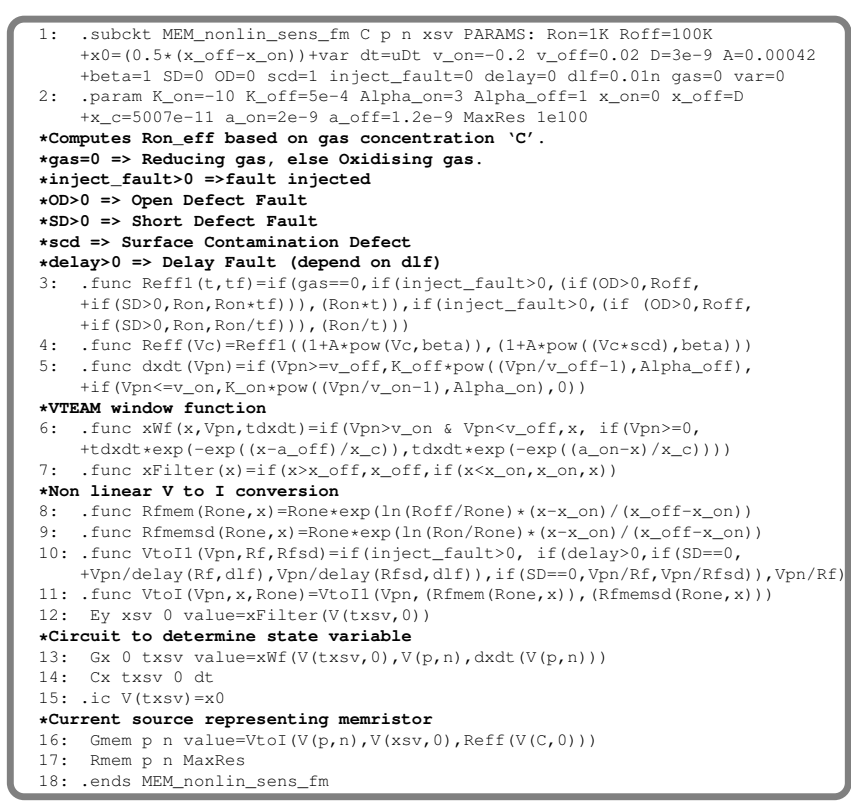

Fig. 1: Proposed Memristor Gas Sensor Model with Incorporated Fault Models (Section II-B).

4) Delay Fault (DLF): This fault causes error/delay in the functioning of a gas sensor based on its timing due to fabrication process effects [8].

\section{B. Spice Modelling with Incorporated Fault Models}

To capture the behaviour of the memristor, a model inspired by [4] and [5] is constructed in this paper. The proposed spice model is integrated with different types of defects/faults to determine its effects on the functionality of the sensor. The hysteresis curve of the proposed spice model is shown in Fig. 2a where a sine voltage of $\pm 0.21 \mathrm{~V}$ is applied.

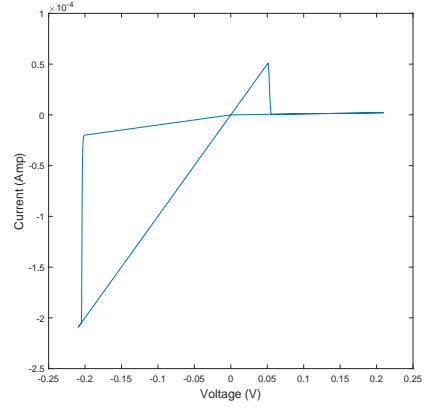

(a)

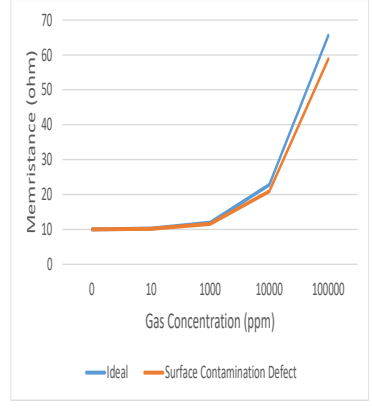

(b)
Fig. 2: (a) I-V Characteristic; (b) Effect of SCD on the memristance vs gas concentration $\left(R_{\mathrm{M}}^{\mathrm{I}}=10 \mathrm{~K}, V_{\mathrm{R}}=20 \mathrm{mV}\right.$, Gas Type=Reducing).

\section{Simulation Results}

For the simulation results, the memristors were coded in spice based on the model in [5] and the systems were designed and simulated in LTSpice. Fig. 1 shows the proposed memristor gas sensor model with incorporated fault models. The model is flexible and satisfies the primary equations of a memristive system, the convergence conditions and computational efficiency required by simulation engines. Table I shows the summary of the defects/faults likely to occur in Memristor based gas sensor based on literature, however the model is flexible so that it can be modified to include observed faults from manufactured device.

TABLE I: Summary of Defects in Memristor based Gas Sensor

\begin{tabular}{|c|c|c|c|}
\hline \multirow{2}{*}{$\begin{array}{c}\text { Defect/Fault } \\
\text { Types }\end{array}$} & \multicolumn{2}{|c|}{$\begin{array}{l}\text { Source } \\
\end{array}$} & \multirow{2}{*}{ Observation } \\
\hline & Doping & Others & \\
\hline Ideal & Normal & - & Defect free memristor \\
\hline \multirow{2}{*}{ Open } & $\begin{array}{c}\text { Insufficient/ } \\
\text { Undoped }\end{array}$ & - & \multirow{2}{*}{$\begin{array}{l}\text { Always at high } \\
\text { memristance irresp. } \\
\text { of the gas } \\
\text { applied across it }\end{array}$} \\
\hline & 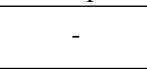 & $\begin{array}{l}\text { 'open' within } \\
\text { the cell }\end{array}$ & \\
\hline \multirow{2}{*}{ Short } & $\begin{array}{l}\text { Fully } \\
\text { doped }\end{array}$ & 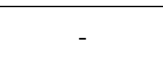 & \multirow{2}{*}{$\begin{array}{l}\text { Always at low } \\
\text { memristance irresp. } \\
\text { of the gas } \\
\text { applied across it }\end{array}$} \\
\hline & - & $\begin{array}{l}\text { 'short' within } \\
\text { the cell }\end{array}$ & \\
\hline $\begin{array}{l}\text { Surface } \\
\text { Cont. } \\
\text { (Fig. 2b) }\end{array}$ & - & $\begin{array}{l}\text { Impurities on } \\
\text { the oxide } \\
\text { surface }\end{array}$ & $\begin{array}{l}\text { Incorrect/Reduced } \\
\text { change in memristance } \\
\text { after exposure } \\
\text { to } C \mathrm{ppm} \text { of gas }\end{array}$ \\
\hline Delay & - & $\begin{array}{c}\text { Fabrication } \\
\text { process } \\
\text { effects }\end{array}$ & $\begin{array}{l}\text { Errors/delay in the } \\
\text { functioning of a } \\
\text { gas sensor based } \\
\text { on its timing }\end{array}$ \\
\hline
\end{tabular}

\section{CONCLUSION}

In this paper, we developed and proposed a memristor based gas sensor spice model with integrated fault models capable of demonstrating the consequence of the defects/faults on the gas sensor. The model is simple, flexible and could be modified to include observed faults from manufacturing devices. The model incorporates functional programming style for efficiency and correctness. The proposed model can easily fit to any practical memristive device and has been implemented in LTSpice simulation.

\section{ACKNOWLEDGMENT}

The work was funded by the Leverhulme Trust Research Project Grant, under Grant No.RPG-2017-344.

\section{REFERENCES}

[1] D. B. Strukov, G. S. Snider, D. R. Stewart and R. S. Williams, "The Missing Memristor Found," Nature, vol. 453, pp. 80-83, May 2008.

[2] N. Barsan, C. Simion, T. Heine, S. Pokhrel, and U. Weimar, "Modeling of sensing and transduction for p-type semiconducting metal oxide based gas sensors," J Electroceram., vol. 25, no. 1, pp. 11--19, Aug. 2010.

[3] A. Adedotun, J. Mathew, A. Jabir, C. D. Natale, E. Martinelli and M. Ottavi, "Efficient Sensing Approaches for High-Density Memristor Sensor Array," J Comput Electron., vol. 17, no. 3, pp. 1285-1296, Sep. 2018.

[4] S. Kvatinsky, E. G. Friedman, A. Kolodny and U. C. Weiser, "TEAM: Threshold Adaptive Memristor Model,” IEEE Trans. Circuits Syst. I, Reg. Papers, vol. 60, no. 1, pp. 211-221, Jan. 2013. 
[5] S. Kvatinsky, M. Ramadan, E. G. Friedman and A. Kolodny, "VTEAM: A General Model for Voltage-Controlled Memristors," IEEE Transactions on Circuits and Systems II: Express Briefs, vol. 62, no. 8, pp. 786-790, Aug. 2015.

[6] O. Kavehei, A. Iqbal, Y. S. Kim, K. Eshraghian, S. F. Al-Sarawi, and D. Abbott, "The fourth element: characteristics, modelling and electromagnetic theory of the memristor," Proceedings of the Royal Society Mathematical, Physical and Engineering Sciences, 2010, pp. 2175--2202.

[7] Corrosionpedia.com, 'Surface Contaminants', [Online]. Available: https://www.corrosionpedia.com/definition/1712/surfacecontaminants-environmental-conditions.

[8] M. Sivaraman and A. J. Strojwas, "Delay fault coverage: a realistic metric and an estimation technique for distributed path delay faults," Proceedings of International Conference on Computer Aided Design, San Jose, CA, USA, 1996, pp. 494-501. 